\title{
TU/e EmonOWEN

\section{Improvement of the dynamic performance of an AC linear permanent magnet machine}

\section{Citation for published version (APA):}

Jansen, J. W., Lomonova, E., Vandenput, A. J. A., Compter, J. C., \& Verweij, A. H. (2003). Improvement of the dynamic performance of an AC linear permanent magnet machine. In IEEE international electric machines and drives conference (IEMDC '03), June 1-4, 2003, Madison, Wisconsin, USA. Vol. 2 (pp. 785-790). Institute of Electrical and Electronics Engineers. https://doi.org/10.1109/IEMDC.2003.1210325

DOI:

10.1109/IEMDC.2003.1210325

Document status and date:

Published: 01/01/2003

\section{Document Version:}

Publisher's PDF, also known as Version of Record (includes final page, issue and volume numbers)

\section{Please check the document version of this publication:}

- A submitted manuscript is the version of the article upon submission and before peer-review. There can be important differences between the submitted version and the official published version of record. People interested in the research are advised to contact the author for the final version of the publication, or visit the $\mathrm{DOI}$ to the publisher's website.

- The final author version and the galley proof are versions of the publication after peer review.

- The final published version features the final layout of the paper including the volume, issue and page numbers.

Link to publication

\section{General rights}

Copyright and moral rights for the publications made accessible in the public portal are retained by the authors and/or other copyright owners and it is a condition of accessing publications that users recognise and abide by the legal requirements associated with these rights.

- Users may download and print one copy of any publication from the public portal for the purpose of private study or research.

- You may not further distribute the material or use it for any profit-making activity or commercial gain

- You may freely distribute the URL identifying the publication in the public portal.

If the publication is distributed under the terms of Article 25fa of the Dutch Copyright Act, indicated by the "Taverne" license above, please follow below link for the End User Agreement:

www.tue.nl/taverne

Take down policy

If you believe that this document breaches copyright please contact us at:

openaccess@tue.nl

providing details and we will investigate your claim. 


\title{
Improvement of the Dynamic Performance of an AC Linear Permanent Magnet Machine
}

\author{
J.W. Jansen ${ }^{1}$, E.A. Lomonova ${ }^{1}$, A.J.A. Vandenput', J.C. Compter ${ }^{2}$, A.H. Verweij ${ }^{3}$ \\ ${ }^{1}$ Eindhoven University of Technology \\ ${ }^{2}$ Eindhoven University of Technology \\ Mechanical Engineering Department \\ Den Dolech 2 \\ Den Dolech 2 \\ 5612 AZ Eindhoven, The Netherlands \\ 5612 AZ Eindhoven, The Netherlands \\ ${ }^{3}$ ASM Lithography \\ De Run 6501 \\ 5504 DR Veldhoven, The Netherlands
}

\begin{abstract}
This paper discusses the controller design and test approaches leading to the performance improvement of a brushless 3-phase ac synchronous permanent magnet linear machine. The feasible controller design concept for the linear machine is presented and further implemented in Simulink and dSPACE. Two controllers, a PD and a PID-controller, are designed to reach high position accuracy during constant speed operation without a settling time. The controllers for the linear machine are implemented and the theoretical results are verified.
\end{abstract}

\section{INTRODUCTION}

Linear permanent magnet machines combine high speed and position accuracy. Hence, these machines are popular as long-stroke actuators in manufacturing equipment like pickand-place-machines and wafer scanners. All these production machineries demand fast and accurate positioning stages with minimal delays and settling times to maximize the production output. The initial electromagnetic design, the power amplifier and the controllers determine the maximum reachable performance of the stage.

Fig. 1 shows a picture of the iron-core linear machine. In Table 1 the parameters of the linear drive are summarized. The controller for this linear motor must reach high position accuracy during constant speed (scanning) operation. Furthermore, no settling is allowed. The settling time is defined (Fig. 2) as the time between the moment that the speed reference reaches constant speed and the moment that the position error is within its tolerated limits $( \pm 4 \mu \mathrm{m})$.

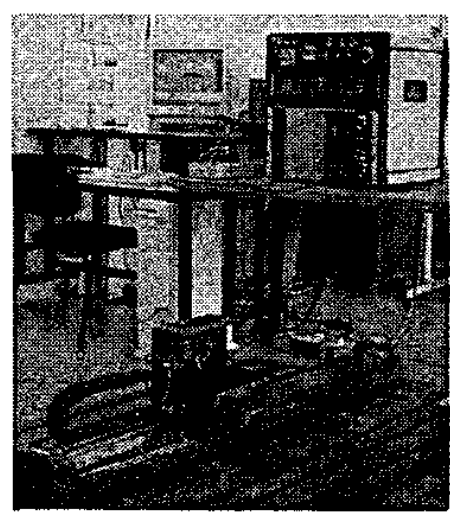

Fig. 1. Test setup with the linear motor.
TABLE 1

SPECIFICATIONS OF THE LINEAR DRIVE

\begin{tabular}{|l|l|}
\hline \multicolumn{2}{|l|}{ Linear tootor (designed by Philips CFT) } \\
\hline stator length & $1.4 \mathrm{~m}$ \\
stator width & $0.06 \mathrm{~m}$ \\
pole pitch, $\tau_{\mathrm{i}}$ & $0.012 \mathrm{~m}$ \\
maximum force & $800 \mathrm{~N}$ \\
motor constant, $K_{\mathrm{t}}$ & $72.55 \mathrm{~N} / \mathrm{A}$ \\
damping, $D$ & $15 \mathrm{Ns} / \mathrm{m}$ \\
translator mass, $m$ & $8.75 \mathrm{~kg}$ \\
\hline Position encoder & \\
\hline encoder type & incremental \\
step size & $1 \mu \mathrm{m}$ \\
maximum error & $5 \mu \mathrm{m}$ \\
maximum speed & $2 \mathrm{~m} / \mathrm{s}$ \\
\hline Current source & Philips ACPA 220/12 \\
\hline dSPACE-board & DS1103 \\
\hline
\end{tabular}

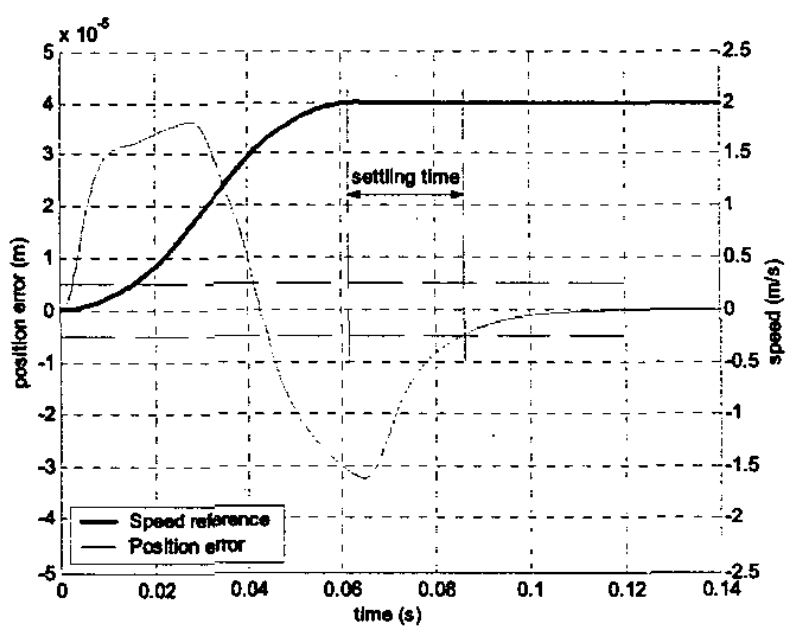

Fig. 2. Used definition of the settling time.

The paper describes the design of two controllers and the implementation of the linear drive in Simulink and dSPACE. First, the PD-controller is implemented. This controller causes a mean position error during constant speed, which can be compensated by a Coulomb friction feedforward controller. The second controller is the PID-controller. This controller eliminates the position error during constant speed operation, but introduces a settling time, which is compensated with the observer. A cogging feedforward controller is implemented with both controllers to reduce the rms-position error. 


\section{MOTOR MODEL}

The electromagnetic force $(F)$, generated by a not-saturated 3-phase linear machine [1] with phases $a, b$ and $c$ is equal to:

$$
F=K_{p h}\left(\begin{array}{l}
i_{a} \sin \left(\frac{\pi}{\tau_{s}} x-\varphi_{x}\right) \\
+i_{b} \sin \left(\frac{\pi}{\tau_{s}} x-\varphi_{x}-\frac{2}{3} \pi\right) \\
+i_{c} \sin \left(\frac{\pi}{\tau_{s}} x-\varphi_{x}+\frac{2}{3} \pi\right)
\end{array}\right)
$$

If the phase currents are equal to:

$$
\begin{aligned}
i_{a} & =\hat{i} \sin \left(\frac{\pi}{\tau_{s}} x+\varphi\right), \\
i_{b} & =\hat{i} \sin \left(\frac{\pi}{\tau_{s}} x-\frac{2}{3} \pi+\varphi\right), \\
i_{c} & =\hat{i} \sin \left(\frac{\pi}{\tau_{s}} x+\frac{2}{3} \pi+\varphi\right),
\end{aligned}
$$

then the force can be written as:

$$
F=\frac{3}{2} K_{p h} \hat{i} \cos (\varphi)=K_{r} \hat{i} \cos \left(\varphi-\varphi_{x}\right),
$$

where

$K_{p h}$ is the motor constant per phase (N/A),

$K_{t} \quad$ is the motor constant (N/A),

$i$ is the phase current (A),

$x \quad$ is the position of the translator $(m)$,

$\tau_{s} \quad$ is the pole pitch (m),

$\varphi_{x} \quad$ is an unknown phase angle (rad), which accounts for the unknown position of the translator,

$\varphi \quad$ is the phase angle of the currents to be set equal to the unknown angle $\varphi_{x}$ in order to maximize the force (rad).

From equation (5), it can be seen that the force depends on the position of the translator relative to the stator. Because the linear motor uses an incremental encoder, the initial position of the translator with respect to the stator is unknown. An alignment procedure is used to determine the value of $\varphi$ to maximize the force [2].

The mechanical part of the system is modelled by the translator mass $m$ and damping $D$. The values of these parameters and the value of the motor constant $K_{t}$ are summarized in Table 1 .

\section{PD-CONTROLLER}

The advantage of a properly designed PD-controller is that the settling time is negligible. However, feedforward control for all major disturbances have to be implemented to reduce the mean position error during constant speed operation.

The gains of the proportional and derivative feedback of the controller are calculated so that the closed loop system is critically damped and has a bandwidth of $100 \mathrm{~Hz}$. The implementation of a controller with such relative high bandwidth is only possible if the mechanical resonance frequencies of the positioning system are far outside this bandwidth.

\section{A. Velocity observer}

The PD-controller needs both position and speed measurements. The incremental encoder measures only the position of the translator of the linear motor. Direct differentiation of the position signal of the linear encoder does not produce a precise and noise free velocity signal. For this reason, a closed loop velocity observer is used to determine the speed of the translator. The velocity observer contains the motor model and simulates the system behavior because it has the same current input as the linear motor. By feeding back the position through a PID-controller in the observer, the error between the real linear motor and the model in the observer is removed. The bandwidth over which the observer differentiates the position must be higher than the bandwidth of the PD-controller, otherwise it will limit the controller performance [3].

Fig. 3 shows two different observers, which have been compared. The estimated velocity of 'observer 1' is the output of the motor model in the observer [4]. The output of 'observer 2' is the sum of the output of observer 1 and the derivative feedback of the position error [5]. The difference between both observers is shown in the Bode diagram of the transfer function between position input and velocity output of the observers in Fig. 4.

Both observers differentiate the position input for the lower frequencies. However, observer 2 amplifies the position input for the higher frequencies and feeds the noise from the encoder through the gain Ko_d of the observer and derivative gain of the PD-controller back to the power amplifier and the linear motor. This results in (audible) noise in the linear motor. Observer 1 integrates the position input for the higher frequencies and filters it.

The disadvantage of observer 1 is that, contrary to observer 2, the estimated velocity contains an error, which causes a position error of the translator if there is no integral feedback in the observer.

Observer 1 has been implemented in the controller of the linear motor. The bandwidth is set to $300 \mathrm{~Hz}$.

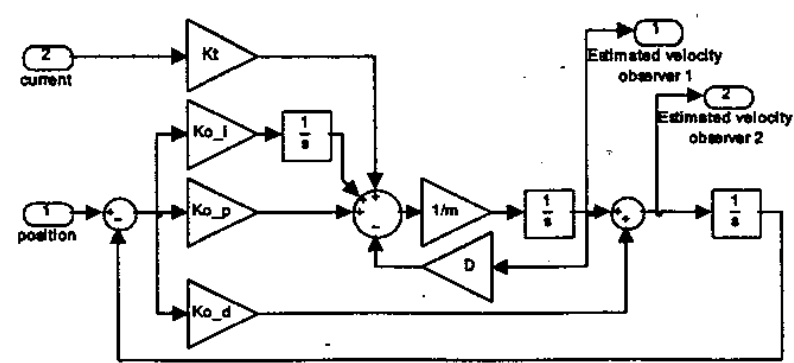

Fig. 3. Two observers with different estimated speed outputs. Ko_p, Ko_d and $\mathrm{Ko} i \mathrm{ire}$ the gains of the proportional, derivative and integral feedback, respectively. 


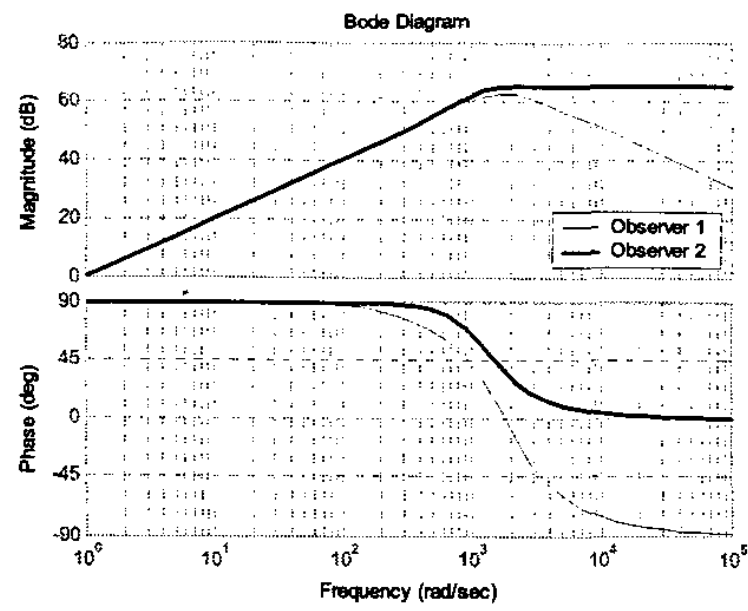

Fig. 4. Bode diagram of both observers.

\section{B. Feedforward controller for damping and mass}

The closed system has a steady state error without the feedforward controller for the damping of the motor. A feedforward controller for the mass significantly reduces the position error during acceleration. The currents, which neutralize the effects of the damping and the mass of the translator, can be calculated straightforward and are derived, respectively:

$$
\begin{gathered}
i=\frac{D}{K_{t}} v, \\
i=\frac{m}{K_{t}} a .
\end{gathered}
$$

\section{Feedforward controller for the Coulomb friction}

A feedforward controller for the Coulomb friction is an essential part of the PD-controller. The average position during constant speed is not equal to $0 \mu \mathrm{m}$ without this feedforward controller. Although the friction is hard to model properly, the implementation of the simplest model of the Coulomb friction in the feedforward controller performs well. The Coulomb friction is compensated by a constant current, which sign depends on the direction of the velocity. Fig. 5 shows that the Coulomb friction feedforward controller can eliminate the average position error during constant speed. The value of the Coulomb friction is equal to $19 \mathrm{~N}$.

\section{Feedforward controller for the cogging forces}

The interaction, between the teeth of the translator and the individual magnets on the stator of the linear motor, cause cogging forces. This disturbance leads to a position dependent error. This error can be estimated independent of the zero position of the translator. It is measured with respect to the phase of the current in one motor phase, since the phase of the current in an ac synchronous motor is determined by the relative position of the motor phase above the magnets. Every phase angle corresponds with a relative position above the magnets.
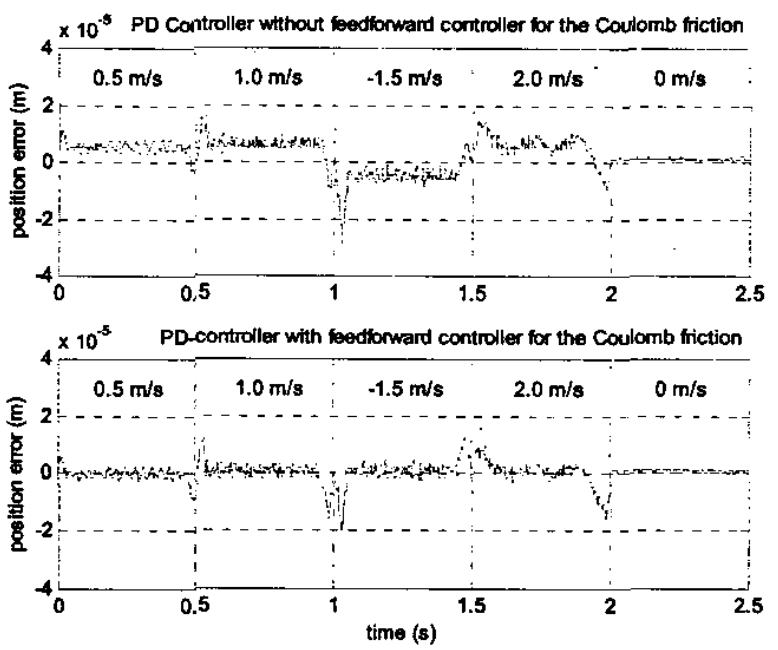

Fig. 5. Effect of the feedforward controller for the Coulomb friction for different speeds.

Fig. 6 shows the distribution of the position error as function of the phase of the current in one motor phase at three different speeds, measured over a stroke of $1 \mathrm{~m}$. Although the measurement contains much noise caused by errors from the encoder and force ripples, a sinusoidally shaped trend with the double frequency of the motor current can be recognized. Potentially, this trend could be linked to cogging forces but the implementation of a speed independent feedforward signal offered no solution. However, the introduction of a feedforward signal, which is quadratically proportional to the speed, removes the sinusoidal trend. The origin of this phenomenon is the subject of further investigation and requires better sensor resolution than available.
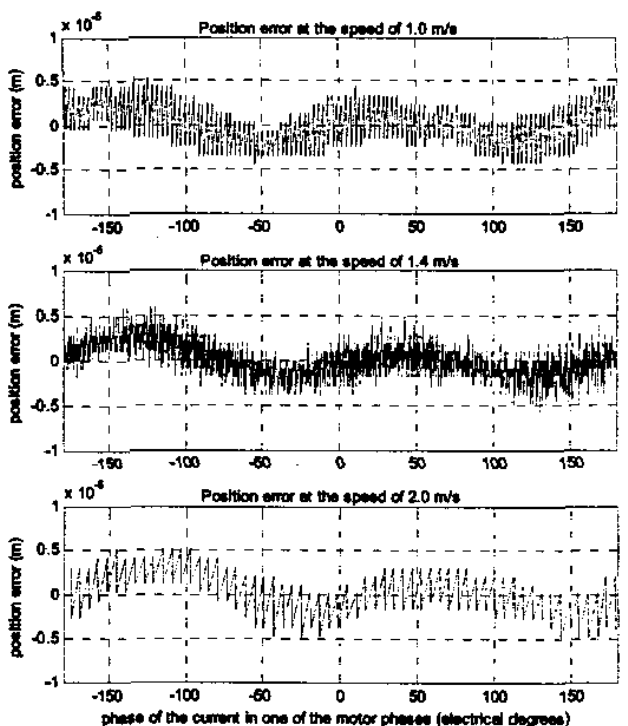

Fig. 6. Position errors at different constant speeds as function of the phase of the current in one phase of the motor, which are measured during a movement of $1 \mathrm{~m}$ of the translator. 
Fig. 7 shows the implementation of this feedforward signal. The amplitude and the relative phase of the compensating current are tuned for a translator speed of $2 \mathrm{~m} / \mathrm{s}$. The selected value for the amplitude of the current is $0.22 \mathrm{~A}$. The particular value of -117 electrical degrees is selected for the phase but it generally depends on the position of the encoder sensor.

Fig 8. shows the effect of the compensation for the same speeds as in Fig. 6. The position error at constant speed is reduced from $\pm 7 \mu \mathrm{m}$ to $\pm 4 \mu \mathrm{m}$.

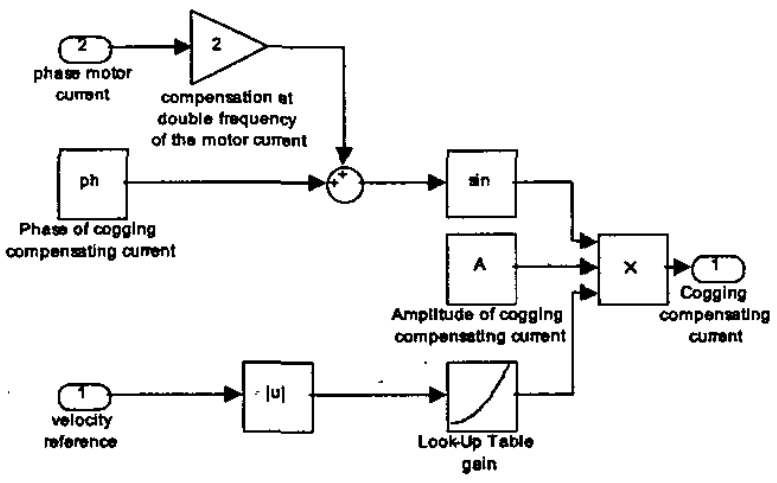

Fig. 7. Feedforward controller for the cogging forces. The amplitude $(A)$ and the value of the phase $(p h)$ of the compensating sine wave are tuned for one speed. The look-up table, containing the quadratic relationship, is used to adjust the amplitude for other speeds.
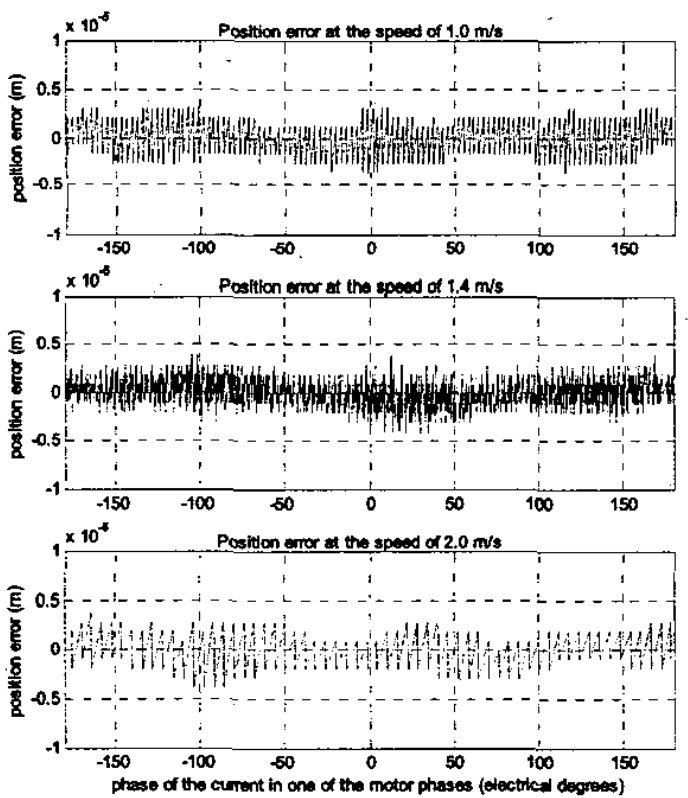

Fig. 8. Position errors with the feedforward controller for the cogging forces at different constant speeds as function of the phase of the current in one phase of the motor, which are measured during a movement of $1 \mathrm{~m}$ of the translator.

\section{PID-CONTROLLER}

The performance of the feedforward controllers, which are implemented with the PD-controller, for example, the compensation for the Coulomb friction, is strongly dependent on the correctness of the controller parameters. Implementing a PID-controller can decrease the sensitivity to these parameters or the necessity of those feedforward signals. However, the integral feedback, which eliminates the average position error during constant speed operation, introduces a settling time because the integration takes time. Furthermore, a too high integral feedback gain will increase the rms-position error.

Normally, the motor parameters and the parameters of the motor model in the observer are the same. However, a property of observer 1 is that the damping of the observer can be used to influence the transient behaviour of the controller. The damping in the observer can be used to control the overshoot of the step-response and to decrease the speed error of the observer during acceleration. The settling time of the linear motor can be sufficiently reduced by increasing the damping of the observer from $15 \mathrm{Ns} / \mathrm{m}$ to $100 \mathrm{Ns} / \mathrm{m}$. Two PID-controllers with these damping coefficients in the observer are designed for comparison with the PD-controller. Both PID-controllers use observer 1, the feedforward controllers for the mass, damping and cogging forces and have a bandwidth of $100 \mathrm{~Hz}$.

Fig. 9. shows the position error, when the speed of the translator is changed from $+2 \mathrm{~m} / \mathrm{s}$ to $-2 \mathrm{~m} / \mathrm{s}$ with maximal force. The position, speed, acceleration and jerk references are specified in the Appendix (Fig. 11). These measurements are done for the PD-controller and two PID-controllers. The PID-controller with the normal damping of the linear motor in the observer $(15 \mathrm{Ns} / \mathrm{m})$ has a settling time of $7.5 \mathrm{~ms}$. The PD-controller and the PID-controller with the increased damping have no settling time.

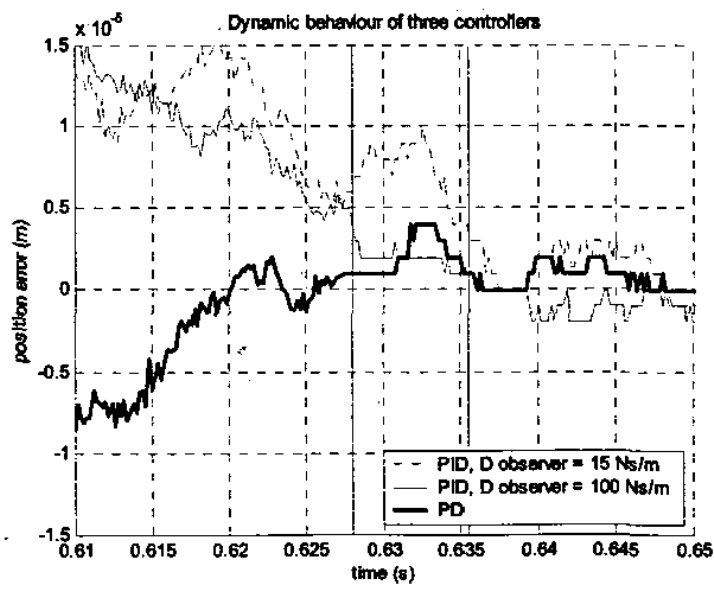

Fig. 9. Dynamic behaviour of the PD controller, the PID controller and the PID-controller with extra damping in the observer. The left vertical line indicates the time at which constant speed should be reached and the position error minimized. The second vertical line indicates the moment that the PIDcontroller with the normal damping has settled. 
The linear positioning system can make less correct movements (a scan with a certain length at constant speed with minimal position error) per hour if the controller has a settling time. The number of scans per hour for the system with the settling time is $2.3 \%$ less compared to the system without settling time if the length of the scan is $1 \mathrm{~m}$ and the speed is equal to $2 \mathrm{~m} / \mathrm{s}$. If the length of the scan is equal to $0.2 \mathrm{~m}$ the loss of production is more than $5 \%$.

\section{IMPLEMENTATION OF THE CONTROLLERS IN DSPACE}

In order to validate the control system topologies, the controllers are implemented in Simulink and dSPACE. The flexible architecture of the dSPACE system allows a fast review and debugging of controller designs. Fig. 10 shows the implementation of the controller in Simulink. This model is used to program the dSPACE system. The sample frequency of the dSPACE system is $5 \mathrm{kHz}$.

The main part of Fig. 10 shows the feedback and feedforward controllers. Besides there are three other functional blocks:
- The 'Trajectory generator' block generates the motion profiles. The outputs are a position, speed and acceleration reference. The trajectory generator is written in $\mathrm{C}$ and implemented as an s-function.

- The other s-function 'alignment' contains the initial alignment procedure, which adjust the phase angle of the current, $\varphi$, to the unknown phase angle $\varphi_{x}$. After the alignment the translator is moved to its initial position. For that purpose, a simple controller is implemented in the s-function, which uses the position and speed signals from the encoder. Thereafter, the s-function resets all the integrators in the controller and enables the controller. Besides, this block is responsible for the calculation of the translator position from the encoder signal and the calculation of the phase of the current for one motor phase.

- The 'dSPACE subsystem' is the interface between the controller and linear motor. The current amplitude, which is calculated by the controller, and the phase of the current are converted to the reference signals for the three motor phases by the 'dSPACE subsystem'-block. It also receives the encoder and signals of the end-switches of the motor.

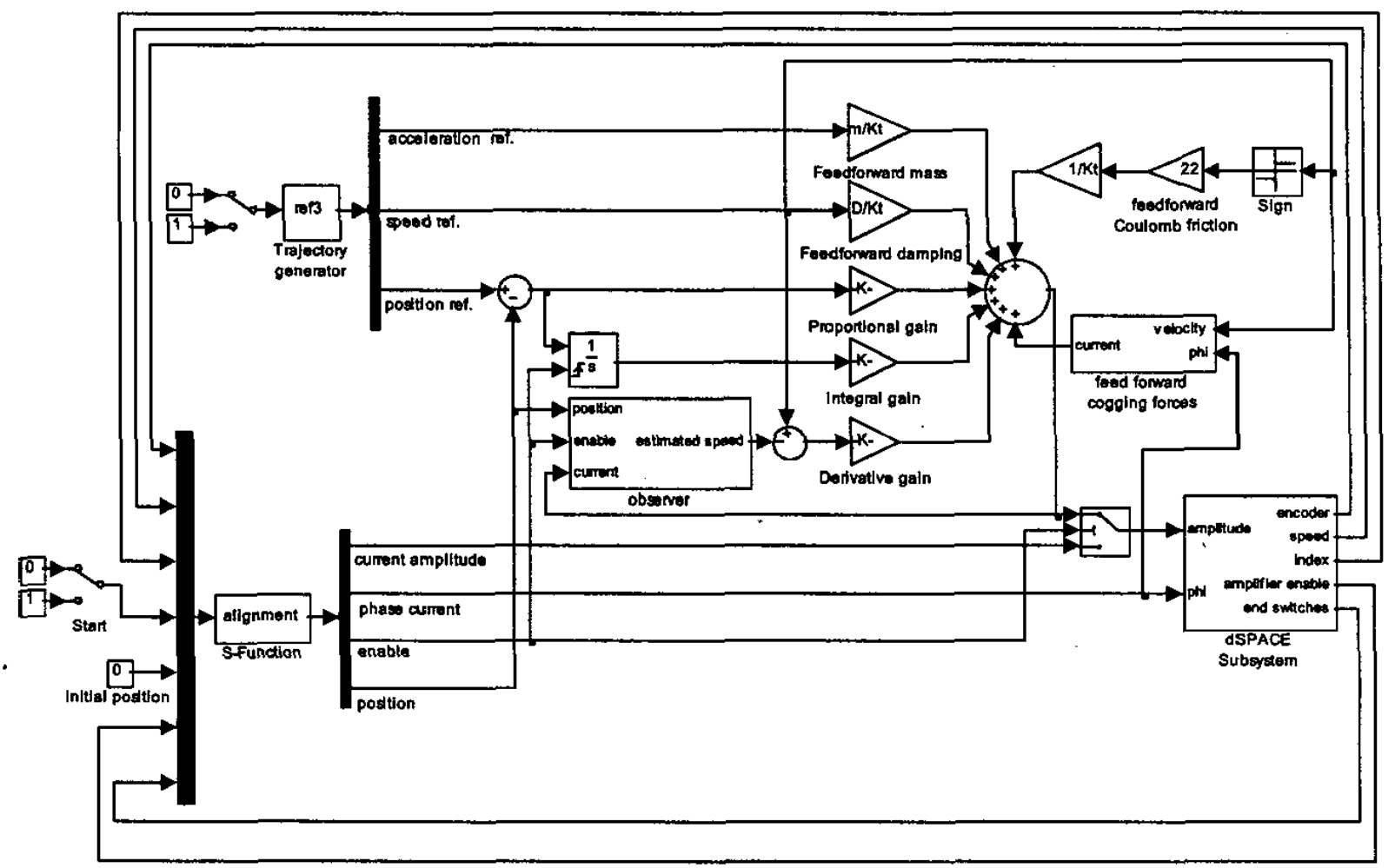

Fig. 10. Implementation of the PID-controller in Simulink 


\section{CONCLUSIONS}

Two controller types have been tested to improve the performance of an ac synchronous permanent magnet linear motor. The motor model and the controller designs have been verified with experimental results. Both the PD-controller with the feedforward controller for the Coulomb friction, and the PID-controiler with extra damping in the observer can control the linear motor without a settling time and without an average position error during constant speed operation. Its realization enables to meet the target of performance improvement. Due to the implementation of feedforward controllers the position error can be reduced to the level of accuracy of the measurement system. This accuracy level limits the further investigation of the position error during constant speed.

\section{APPENDIX}

Trajectory used to test the dynamic behaviour of the controllers in section IV is shown in Fig. 11.
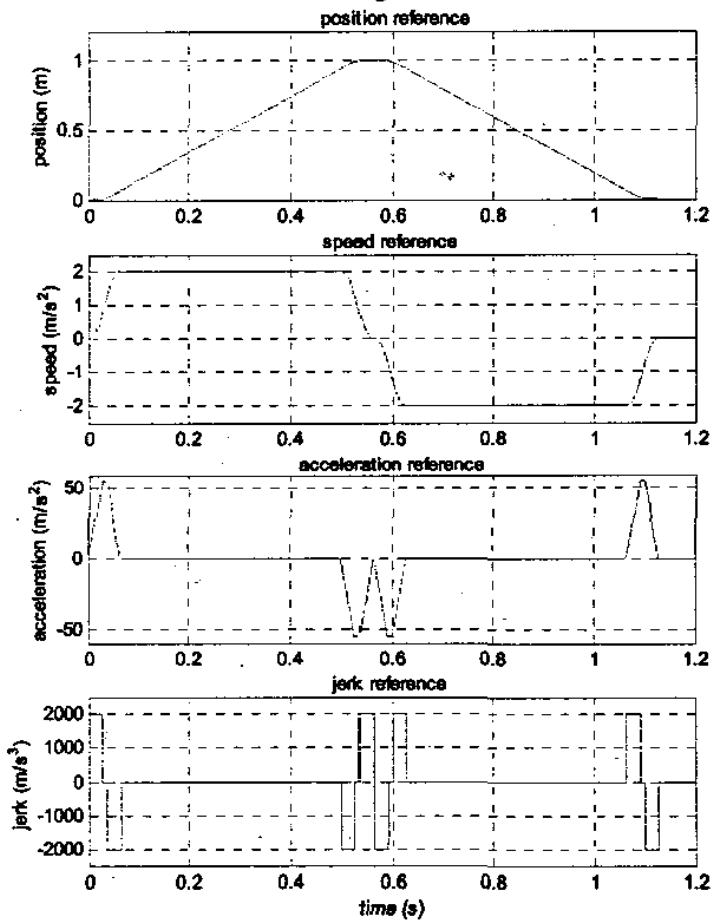

Fig. 11. Position, speed, acceleration and jerk references of the used trajectory.

\section{ACKNOWLEDGEMENT}

The authors thank Philips CFT for the placement of the linear motor system at their disposal and are also grateful to Johan van Doorn and Marijn Uyt de Willigen for their help during the measurements.

\section{REFERENCES}

[1] Polinder, H, Slootweg, JG, Compter, JC, Hoeijmakers, MJ, "Modeling a linear PM motor including magnetic saturation", IEEProceedings 437, pp. 632-637, 2002.

[2] Bleijenberg, $R$, "Drive arrangement and motor-energising system for use in the arrangement," US Patent 4,888,543, 1989.

[3] Franklin, GF, Powell, JD, Emami-Naeini, A, "Feedback control of dynamic systems", Third edition, Addison-Wesley Publishing Compary, Reading, UK, 1994.

[4] Lorenz, RD, Van Patten, KW, "High resolution velocity estimation for all-digital, AC servo drives", IEEE Trans. on Industry Applications, vol 27, no 4, 701-705, Jul/Aug 1991.

[5] Sheng-Ming Yang, Shuenn-Jenn Ke, Performance evaluation of a velocity observer for accurate velocity estimation of servo motor drives, IEEE Trans. on Industry Applications, vol 36, no 1, pp. 98. 104, Jan/Feb 2000. 